diabetes in one case, with hypertension in 3 cases and with focal infection in one case. No general or focal disturbances could be found in any.

As to local disturbances, in one case there was no disturbance except a slight hyperopia. in 5 cases there were cataracts of incipient or immature stages. This was associated with senile macular degeneration in one, and circinate retinopathy in the other.

In the majority of cases, the cholesterin content of the blood, although within normal limits, was somewhat increased.

Possibly some changes in the composition of the blood may cause the deposition; and local disturbances may act as a precipitating factor. Thus association with some general disturbance or focal infection, structural changes of the lens, circinate retinopathy, or senile macular degeneration may be the cause of deposits. But since the lens changes and macular degenerations are bilateral, the monocular incidence of scintillatio albescens needs some further explanation.

We applied treatment according to the general or local disturb. ances, but could not see any improvement in the fundus picture.

\title{
REFERENCES
}

DUKE-ELDER-Text-book of Ophthalmology, Vol: III, p. 3249, 1940.

JEss, A. - Kurzes Handbuch der Ophthalmologie, füntter Band, S. 346, 1930.

Кову, F. Ed.-Traité d'Ophtalmologie, Tome IV, p. 27, 1939.,

Troncoso, M. U.-Internal diseases of the eye and atlas of ophthalmology, p. $495,1937$.

\section{CONGENITAL CYCLOPIA AND ORBITAL CYST TOGETHER WITH OTHER DEVELOPMENTAL ANOMALIES ON THE SAME SIDE OF THE FACE}

BY

\section{F. PapolcZY \\ BODAPEST}

AcCoRDing to Seefelder there are four groups of developmental anomalies of the whole eyeball :

(1) Mikrophthalmus congenitus;

(2) Anophthalmos congenitus ;

(3) Mikrophthalmos seu anophthalmos congenitus et cysta orbitae ;

(4) Cyclopia.

Congenital anophthalmos is mostly a developmental anomaly of both sides, more rarely of one side only, according to literature.

${ }^{*}$ Communication of the Municipal St. Stephen Hospital of Budapest, Ophthalmological Department (Chief physician: F. Papolczy, M.D.). Received for publication, April 12, 1948. 
The rudiments of the eyeball, however, can nearly always be found by clinical or by microscopic examination of the soft parts of the orbit. For this reason it is impossible to distinguish exactly extreme degrees of congenital microphthalmos from anophthalmos. This anomaly is nearly always to be seen together with an orbital cyst. The cyst is sometimes so large that it causes the eyelid to bulge, in other cases so small that it can only be detected by microscopic examination. It mostly forms under the lower lid.

Congenital anophthalmos is a hereditary developmental anomaly. It was sometimes found to be a consequence of intermarriage. In other cases secondary injuries to the embryonal development of the eyeball must be taken into consideration, which may be any sort of injury, even such as caused by experimental research work.

Microscopic examination of the orbital cyst shows that this is of ectodermal origin. It develops in the primary optic vesicle or in the already developed optic cup. When the cyst has developed in the primary optic vesicle, there are but one or more coherent cavities to be found which are filled with a mucuous secretion rich in albumen. They are lined with a tissue which resembles the retina or the pigment epithelium, sometimes similar to glia. If the cyst originates from the already developed optic cup it generally grows very large, and the microphthalmos or rudiment of the eyeball may be found in the orbit.

On February 14, 1947, a boy infant of ten days was sent from the children's ward of the St. Stephen Hospital to the ophthalmological department for examination.

Ophthalmological report: on the right side, above the inner canthus, starting from the inner third of the upper lid, a thick, proboscis-like structure, $3.5 \mathrm{~cm}$. long and $1-1.2 \mathrm{~cm}$. wide hangs down parallel to the nose into the sulcus nasolabialis, its lower end showing a navel-like, deep depression. The lower lid is violetblue, greatly enlarged, hemispherically protruding and like an air-cushion to the touch. It is almost impossible to open the palpebral fissure. There is no eyeball. In its place a conjunctival sac pressed upwards from below is visible. Besides, the baby has a hare-lip and cleft palate. The left side is normal.

Röntgen picture : The right orbit is narrower, in it an increase of shadow about the breadth of a finger from above-outside downwards towards the middle which entirely fills out the orbit in the profile picture.

Operations : On February 17, the proboscis-like structure was removed, on May 17, we excised the cyst which was situated under the lower eyelid. It was almost as large as a nut and filled with a mucous, pale yellow fluid. Both operation wounds healed perfectly. 
Histological report: a section of the proboscis-like structure under the microscope presents a picture resembling the tissue of the nose. The outer wall of the section is formed by several layers of stratified epithelium under which tissue numerous fatand sweat-glands are to be seen. In the centre there is a round small lumen the walls of which consist of epithelium resembling that of the outer wall. Between the two layers of epithelium loose tissue, in some places filled with blood vessels, is present, the lumen is almost entirely surrounded by thin, ring-shaped cartilaginous tissue.

The wall of the cyst is surrounded by tissue fibres and-lined with two, in some places more layers of epithelium, partly presenting a polypus like structure.

On May 24, seven days after the second operation, the baby became feverish; the highest temperature was $39 \cdot 1 \mathrm{C}$. The otologist diagnosed otitis media purulenta of the left ear. Two

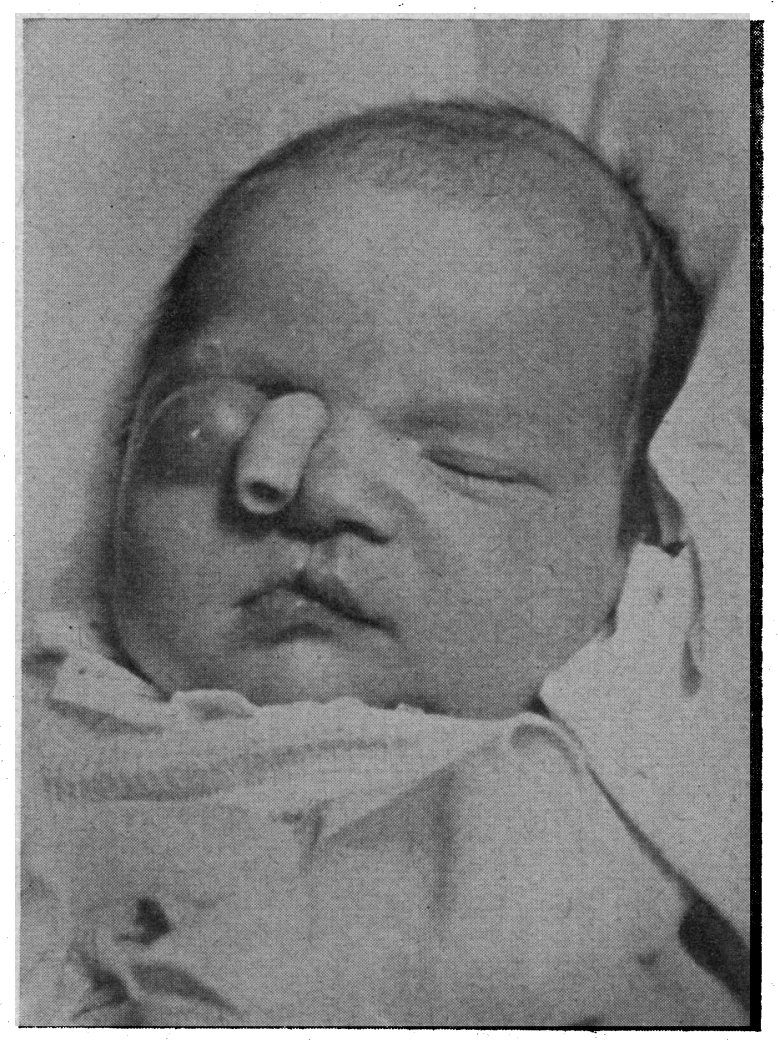

Congenital cyclopia and orbital cyst. 
days later pneumonia set in. In spite of penicillin and other treatment usual in such cases, the baby died on the eighth day of the illness.

Report of the post-mortem examination of the soft parts of the orbit : in the section retina, choroid, ciliary body, iris and particles of the lens are visible in a normal disposition, in many places pigment epithelium is present.

Thus, in my case, the baby had congenital anophthalmos and an orbital cyst on the right side, and, on the same side a proboscis, that is to say a rudimentary nose, further a hare-lip and cleft palate. Under the microscope rudiments of the eyeball were visible in the soft parts of the orbit.

Actually the developmental anomaly I describe here belongs to the " cyclopia "-group, the changes in the eye and nose generally being only a part of the injury to the forebrain.

According to Bock there are the following degrees of cyclopia :

(1) Two separate orbits, situated near to each other, and a rudimentary nose (cebocephalia).

(2) Two separate orbits, so near to each other that the proboscislike nose is above them (arhinencephalia).

(3) Two separate eyes in a common orbit.

(4) The same, but the sclera of both eyes glued together.

(5) Common, but thinner sclera in which are two eyes and the optic nerves close to each other.

(6) One cornea, the other tissues of the eye twofold and the optic nerves attached to each other.

(7) Two lenses in one eye.

(8) One eye.-

This grouping, however, is by no means complete, because many other kinds of anomalies of the development of the eye may occur, from the different forms of coloboma to microphthalmos and anophthalmos.

Freaks born with cyclopia are mostly unable to live.

Besides anomalies of the eye the place of the second proboscislike nose may vary to a great degree. Very often all sorts of other developmental anomalies of the other parts of the face may be seen simultaneously. Consequently it is evident that it is most difficult to classify the different forms of cyclopia and that on account of the many variations of deyelopmental anomalies not two cases are exactly identical.

Lately Meeker and Aebli described a case that was already published in 1942 and 1944 , and that has a resemblance to mine. A boy of $5 \frac{1}{2}$ years had two eyes in a common sclera on the left side, a proboscis (rudimentary second nose) on the same side, and hare-lip and cleft palate as well. 
1. Bоск, A.-Beschreibung eines atypischen Zyklops. Klin. Monatsbl. f. Augenheilk., 1889.

2. MEEKER, L. H. and AEBLI, R.-Cyclopean eye and lateral proboscis with normal one-half face. Arch. of Ophthal., Vol. XXXVIII, p. 159, August, 1947.

3. SCHIECK, F. and BRÜCKNER, A.-Kurzes Handbuch d. Ophthal., Bd. 1, 1930.

4. Seefelder, R.-Missbildungen des menschlichen Auges. Auges.. S. 519-630.

\section{ANNOTATION}

\section{"What's in a Name?"}

The question is one which has often been asked, and in medicine one might be tempted to reply- "a good deal more than was ever meant to be in it, and sometimes the exact opposite." The classical

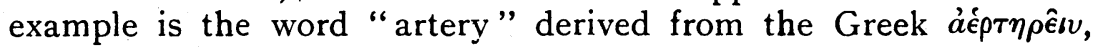
meaning to hold air, and so called because the tubes the words designate were thought to carry air from the heart or trachea, as Trevisa wrote in 1398 " to bere and brynge kindily heete from the herte to all the membres." Any attempt to change artery to a word meaning "carry blood" would, however, rouse strenuous opposition, and could only result in a much less elegant one.

Several examples are to be found in our own branch of medicine, the best known being cataract and glaucoma. "Cataract" has been attributed by some to the ancient theory that it was caused by a fall of inspissated material into the pupil, but others derive it from the second meaning which was " portcullis." This is more rational, because as the portcullis obstructs vision in a gateway, so does the cataract obstruct vision in the eye.

Glaucoma is a useful word, because being meaningless-literally translated, it signifies a gray-green tumour-it serves to cover our uncertainty as to the pathology of the disease.

Hypermetropia and myopia might come in for criticism, since the former means an eye beyond measure-a curious phrase to apply to an eyeball whose usual defect is that it is too small and the latter a closed, and therefore by inference a small eye, but it is doubtful whether micropia and megalopia would ever be accepted as respectively synonymous, even though they described the condition more accurately.

That a knowledge of Classics is not always a help to medical students was demonstrated in an examination held a few years ago at a certain hospital. ' One of the questions consisted in asking the meaning of various ophthalmological terms, among which were epiphora and hyperphoria. Epiphora was correctly defined by a candidate as an overflow of tears, but hyperphoria was beyond him, so he summoned his knowledge of Greek to his aid, and stated that hyperphoria meant a really good cry. 